\title{
RADIATION DISINFESTATION OF HONEYBEE COMBS INFESTED WITH GREATER WAX MOTH EGGS
}

\author{
Mohammed Mansour* \\ Atomic Energy Commission of Syria, Damascus \\ *corresponding author: ascientific30@aec.org.sy \\ Received: 05 March 2019; accepted 24 February 2020
}

A bstract

The sensitivity of different developmental stages of greater wax moth (Galleria mellonella L.) eggs to gamma irradiation was examined. Eggs, 25 to $144 \mathrm{~h}$-old, were exposed at $48 \mathrm{~h}$ intervals to gamma radiation dosages ( 50 to $400 \mathrm{~Gy}$ ), and the effects on egg hatch, pupation and adult emergence were investigated. The developmental rate of irradiated-egg larvae and pupae to adult stage was also studied. Results showed that the irradiation sensitivity of $G$. mellonella eggs decreased with increased age of the eggs when irradiated. In 25-48 h-old eggs, 50 Gy dose significantly reduced egg hatch and at 200 Gy dose no egg hatch was observed. Eggs 73-96 h-old were slightly more tolerant to irradiation treatment; hatching completely ceased at 250 Gy dose. Sensitivity to gamma irradiation reached its lowest level however when 121-144 h-old eggs (few h. before egg hatch) were irradiated. $350 \mathrm{~Gy}$ dose reduced egg hatch to about $3 \%$, and at $400 \mathrm{~Gy}$ no egg hatch was noted. Survival to the adult stage was also negatively affected. At the most radio-tolerant stage (121-144 h-old), $100 \mathrm{~Gy}$ dose significantly reduced larval survival to the adult stage and $300 \mathrm{~Gy}$ completely prevented it. The development rate of larvae and pupae resulting from irradiated eggs was also negatively affected.

Keywords: egg stage, Galleria mellonella, irradiation, radiation disinfestation

\section{INTRODUCTION}

The greater wax moth, Galleria mellonella L., devastates and impacts economically the honeybee, Apis mellifera L., worldwide (Haewoon, Man Young Duck, \& Chang, 1995). The pest is also a potential host for transmitting honeybee disease agents (Charriere \& Imdorf, 1999; Kwadha et al., 2017) and attacks all species of Apis (Nagaraja \& Rajagopal, 2009). Its larvae feed on honeybee wax and also on honey and pollen, which causes destruction of honeybee combs and in some cases complete loss of the colony. Combs in storage, extracted or before extraction, are also subject to moths attack (Rajendran \& Hajira Parveen, 2005; Zhu et al., 2016; Kwadha et al., 2017) and be completely destroyed within a short period of time if not properly protected.

G. mellonella adult females fly at night and deposit their eggs on unprotected honeybee combs and in the cracks of honeybee hives. $A$ few days later, eggs hatch and the first instar larvae crawl into the combs and begin their feeding activity. As they feed on wax combs, larvae spin silk around their feeding premises to protect themselves from attacks causing guard bees to withdraw from infested areas. The moths destroy the combs by boring and feeding on the wax which may lead, particularly in weak hives, to complete destruction of the colony (Kwadha et al., 2017).

Although this moth is a serious pest for beehives, strong and well managed colonies can protect themselves. However, stored honeybee combs are more susceptible to moths attack, and newly stored honeybee combs even in insect proof storage facilities can be infestated (Rajendran \& Hajira Parveen, 2005; Zhu et al., 2016; Kwadha et al., 2017). Although stored honeybee combs could carry any developmental stage of G. mellonella, the possibility of bringing wax moth larvae or pupae on honeybee combs is low as wormy combs would be noticed and removed before storage. Eggs, however, are difficult to be seen on combs and, consequently, the higher possibility of storing honeybee combs with eggs. 
The most frequently used control measure to protect stored honeybee combs are such insecticides as parade chloro benzene, phestoxin and methyl bromide (Goodman et al., 1990; Rajendran \& Hajira Parveen, 2005; Babarinde et al., 2013). These chemicals, however, аге not suitable to protect combs containing honey intended for human consumption (Tananaki et al., 2006) and poisonous for honeybee colonies (Ritter \& Akratanakul, 2006). In addition, the frequent use of insecticides leaves unacceptable chemical residues in the wax (Goodman et al., 1990). Furthermore, the wax moth has developed a relatively high resistance to these insecticides. Therefore, finding an acceptable method for treating honeybee combs before storage would be very useful.

lonizing radiation, particularly gamma radiation, has been used for over thirty years as a phytosanitary treatment to disinfest agricultural products against insect pests (Hallman, 2014; Follett, 2014). This technique has a broad spectrum activity against insect pests, can be applied quickly and does not leave a residue on the product (Ayvas \& Yilmaz, 2015). In addition, treatment with ionizing radiation does not induce a resistance in pest populations and causes, if ever, minimal adverse effects on the quality of the treated commodities. Furthermore, irradiation treatment seems practicable, since bee keepers in USA, Australia and South Africa are already irradiating beehives against important bee diseases. Research is also investigating irradiation as a treatment against fungal and viral pathogens to honeybee (Simone-Finstroma et al., 2018).

This paper presents data on the effects of gamma radiation on the egg stage of the wax moth, G. mellonella. In particular, it examines the effects of gamma radiation on egg hatch, survival of larvae resulting from irradiated eggs to the pupal and adult stages and their rate of development. It also discusses the possible use of ionizing radiation as a disinfestation method for stored honeybee combs potentially infested with G. mellonella eggs.

\section{MATERIAL AND METHODS}

\section{Lab rearing of $G$. mellonella}

Eggs used in these experiments were obtained from a wax moth colony that was maintained in a growth chamber under constant temperature and relative humidity. The colony originated from larvae collected from infested beehives at several locations near the city of Damascus (Syria). Rearing conditions were set at $32 \pm 1{ }^{\circ} \mathrm{C}$, $60 \pm 5 \% \mathrm{RH}$ and total darkness, and under these conditions eggs started to hatch in six days. Genetic variability was maintained through the periodical introduction of G. mellonella males from natural populations into the colony. Wax moth larvae were reared on a diet composed essentially of their natural larval food (bee wax, honey and pollen) in $19 \times 14 \times 5 \mathrm{~cm}$ plastic dishes each containing about $400 \mathrm{~g}$ of the rearing medium. In such a diet, mature larvae leave the diet and pupate at the top of the medium. When close to maturation, folded paper "larval holding" strips were placed at the top of the rearing media to provide pupation sites for mature larvae. Mature larvae were collected daily and incubated under the same conditions of $32 \pm 1{ }^{\circ} \mathrm{C}, 60 \pm 5 \% \mathrm{RH}$ and total darkness for pupation and adult emergence. Emerging adults were transferred into $15 \times 10 \mathrm{~cm}$ cylindrical polyethylene jars for mating and oviposition ("oviposition cages"). Accordion shaped folded paper strips were provided for oviposition and the jar openings were covered with a fine mesh to prevent from moths escaping. The ovipositon paper strips were collected daily and replaced with new ones. The collected paper strips carrying G. mellonella eggs were incubated at $32 \pm 1{ }^{\circ} \mathrm{C}$ and $60 \pm 5 \% \mathrm{RH}$ and transferred into a rearing medium five days later.

\section{Obtaining G. mellonella eggs}

G. mellonella eggs of a certain age were obtained by the confinement of about twenty pairs (males and females) of 1-2 day old wax moth adults in oviposition cages. Eggs were deposited on folded paper ovipositon paper strips that were replaced daily. The strips carrying the eggs were incubated under the same previously 
mentioned conditions of temperature, humidity and photoperiod $\left(32 \pm 1{ }^{\circ} \mathrm{C}, 60 \pm 5 \% \mathrm{RH}\right.$ and total darkness) till they reached the appropriate age for irradiation.

\section{Irradiation}

Wax moth eggs were exposed to gamma radiation in a gamma cell supplied with a Co-60 source (Issledovatel Gamma Irradiator, Techsnabexport Co. Ltd. USSR). The average dose rate at the time of irradiation was approximately $7.7 \mathrm{~Gy} / \mathrm{minute}$, the maximum : minimum dose ratio was about 1.14, and Fricke solution was used to calibrate the absorbed dose. Four Petri dishes, containing each about sixty wax moth eggs 25-144 h-old, at $48 \mathrm{~h}$ increment, were irradiated simultaneously $(n=4)$ at each dose level. Paper strips with eggs on them were placed in $9 \mathrm{~cm}$ Petri dishes in the center of the irradiation chamber and exposed to radiation dosages between 50 and 400 Gy at 50 Gy increments $(50,100,150,200,250,300,350$ and $400 \mathrm{~Gy}$ ). The measured dosages, however, werе $48.1 \pm 0.9,100.0 \pm 1.0,151.2 \pm 1.4,204.8 \pm 3.6$, $254.0 \pm 3.7,304.8 \pm 4.1,355.8 \pm 8.6,407.5 \pm 4.9$, геspectively.

\section{Egg hatch determination}

The paper strips carrying irradiated eggs were returned immediately to the laboratory and incubated under the same conditions for the colony $\left(32 \pm 1^{\circ} \mathrm{C}\right.$ and $\left.50 \pm 5 \% \mathrm{RH}\right)$. The eggs at the appropriate age of 121-144 h-old were placed on the surface of the rearing diet in 19x14x5 cm plastic dishes. Five days later, the paper strips were removed and examined under a binocular microscope, and the number of hatched eggs was noted.

\section{Determination of survival to adults}

The dishes with the diet harboring G. mellonella larvae resulting from experimental eggs were incubated under the same conditions for larval and pupal development. Four weeks later the dishes were provided with larval holding strips and covered with a fine muslin mesh to prevent the escape of emerging moths. On a daily basis, emerging adults in each dish were removed and counted, and their number was recorded. Percentage larval survival to adults was calculated through division of the number of recorded moths by the number of treated eggs. The larval holding paper strips and the rearing medium were examined after the cessation of adult emergence, and the number of dead pupae was recorded. We calculated the total number of pupae in each treatment by adding the number of emerging adults in that treatment to the number of dead pupae found in the "larval holding paper strips" and the diet in that treatment. For the percentage of pupation, the total number of pupae were divided by the number of treated eggs.

\section{Rate of development determination}

We recorded the number of emerging moths from the survival studies every day and tabulated the data at five- day intervals. Percentage emergence every five days was calculated by dividing the number of emerging moths during the five- day period in each treatment by the total number of emerging insects in the same treatment. The emergence date in the control was used as the starting date for recoding emergence.

\section{Data analysis}

In order to present the relationship between radiation dose and egg hatch as well as pupation and adult emergence, data from various experiments were subjected to regression analysis. In addition, experimental data were subjected to analysis of variance, and means were separated at the $5 \%$ level of probability by Fisher's protected least significant difference (LSD) test.

\section{RESULTS}

Results show that radiosensitivity of $G$. mellonella eggs decreased with increasing the age of eggs when irradiated and increased with increasing radiation dose (Fig. 1). Regression analysis shows a significant inverse relation between radiation dose and egg hatch $(P<0.05$, $R^{2}=0.90,0.93$ and 0.92$)$ for eggs irradiated at 25-48, 73-96 and 121-144 h-old respectively. 


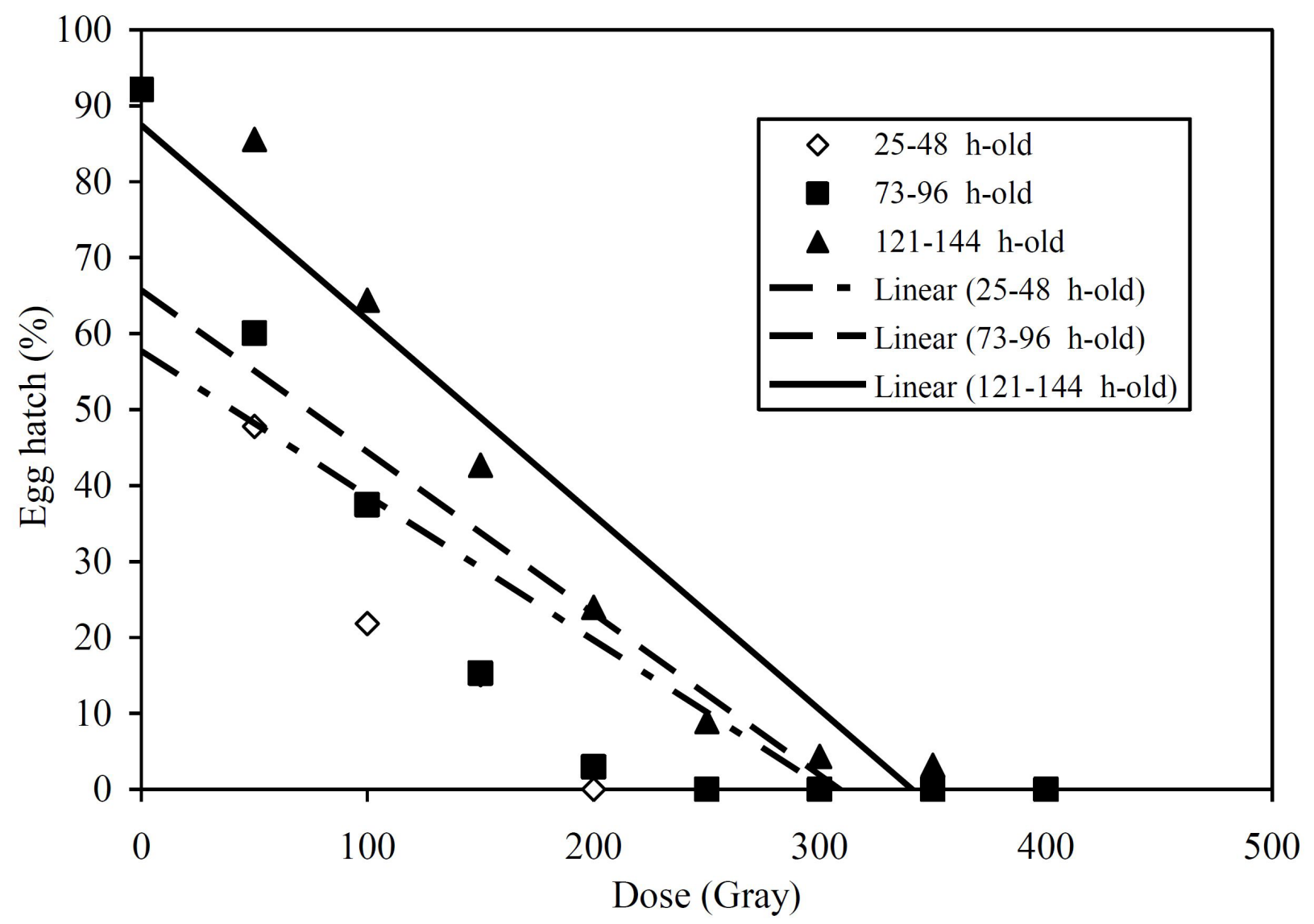

Fig. 1. Effects of gamma radiation on G. mellonella egg hatch.

For instance, 50 Gy significantly reduced egg hatch $(P<0.05)$ in 25-48 h-old eggs, and at 200 Gy egg hatch completely stopped. Eggs 73-96 h-old were slightly more tolerant to irradiation treatment, and egg hatch ceased completely at 250 Gy. However, sensitivity to gamma irradiation reached its lowest level, when 121-144 h-old eggs, a few h. before egg hatching, were irradiated; 350 Gy dose reduced egg hatch to 3\%, and at 400 Gy no egg hatching was observed.

Fig. 2 presents data on the effects of gamma radiation on the survival of $G$. mellonella larvae resulting from irradiated eggs to the pupal stage. Regression analysis shows a significant relationship between radiation dose and percentage survival to the pupal stage $\left(P<0.05, R^{2}=0.84\right.$, $0.9,0.99)$ for larvae resulting from eggs irradiated at 25-48, 73-96 and 121-144 h-old respectively. The data show that at the most tolerant stage (121-144 h-old eggs) 50 Gy significantly reduced larval survival to the pupal stage $(P<0.05)$, and 300 Gy completely prevented it. Examination of the diet showed that 300 Gy not only stopped larval development to the pupal stage but may have also caused their death in the early stages of their development, as no signs of feeding was noticed. Similarly, most larvae resulting from 73-96 h-old eggs exposed to 200 Gy died before pupation, and none of those exposed to 250 Gy reached the pupal stage. Furthermore, all larvae resulting from eggs irradiated at an earlier age (<49 h-old) with 200 Gy or higher failed to reach the pupal stage.

Results on how gamma irradiation affected the survival of $G$. mellonella larvae resulting from irradiated eggs to adults also show a significant correlation ( $\left.P<0.05, R^{2}=0.88,0.87,0.99\right)$ for the same three age groups of eggs (25-48, 73-96 and 121-144 h-old eggs), respectively. Clearly, no pupae from eggs exposed, in the most resistance stage (121-144 h-old eggs), to 300 Gy dose reached the adult stage (Fig. 3). Gamma irradiation affected adult emergence in eggs exposed to irradiation in earlier stages of development more greatly, for example 200 Gy dose prevented adult emergence from 73-96 h-old 


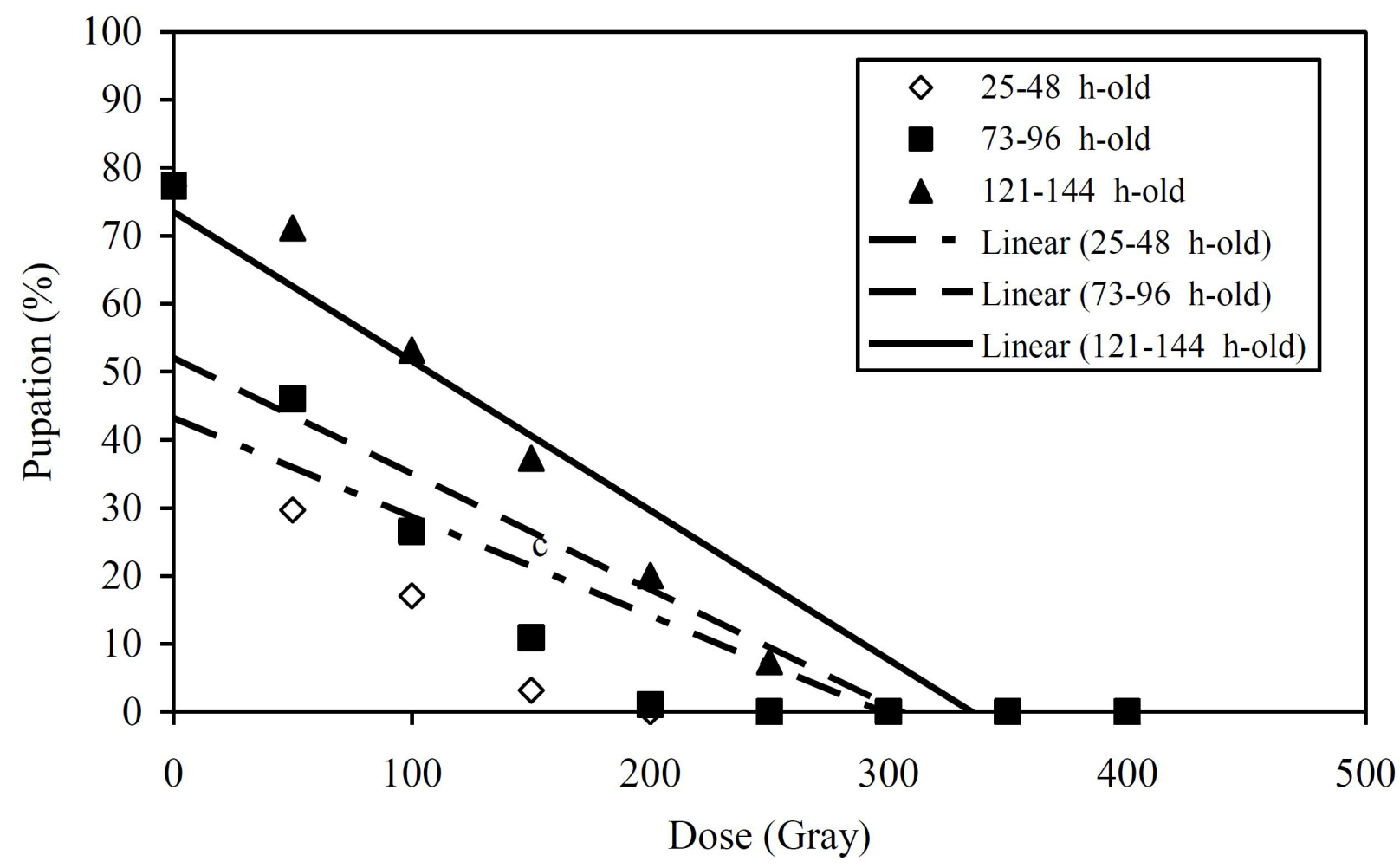

Fig. 2. Effects of gamma radiation on survival of $G$. mellonella larvae resulting from irradiated eggs to the pupal stage.

treated eggs. Fig. 4 presents data on the effects of gamma irradiation on the rate of development of $G$. mellonella immature stages resulted from eggs irradiated a few hours before egg hatch (121-144 h-old). The data clearly shows that the rate of development was negatively affected by irradiation treatment. For instance, while 93.8\% of control moths emerged within fifteen days of the start of emergence, this ratio decreased to $49.4,11.4$ and $7.4 \%$ in larvae from eggs exposed to 50,100 and $150 \mathrm{~Gy}$, respectively. The data (Fig. 4) also show that the time needed for the emergence of the first moth, in comparison with the control, increased with increasing dose.

\section{DISCUSSION}

Phytosanitary treatments are used as a disinfestation and quarantine treatment for agricultural products (Hallman, 2014; Follett, 2014). Disinfestation refers to controlling arthropod pests, particularly insects, infesting fresh or stored agricultural products. Disinfestation techniques include fumigation, heat, cold storage and ionizing radiation, particularly gamma radiation.
The idea of employing ionizing radiation for insect disinfestations of agricultural products goes back to the 1910's. Morgan \& Runner (1913) examined the possibility of using $X$ rays for disinfesting tobacco products of the cigarette beetle, Lasioderma serricorne (F.). Although Runner proved it to be possible (Runner, 1916), the practical applications of this technique were delayed for decades due to the absence of adequately powerful sources of ionizing radiation (Hallman, 2001). The development of sufficiently powerful machines in the second half of the twentieth century, however, revived interest in the subject and ionizing radiation has been used continuously since 1995 to disinfest agricultural products from insect pests.

G. mellonella is one of the most devastating pests of honeybee combs particularly during storage (Rajendran \& Hajira Parveen, 2005). The pest usually enters storage facilities, including insect-proof ones, on newly stored honeybee combs. Current disinfestations methods depend on chemical treatments, particularly chemical fumigants, but this method has many drawbacks including insecticide resistance, lack of adequate 


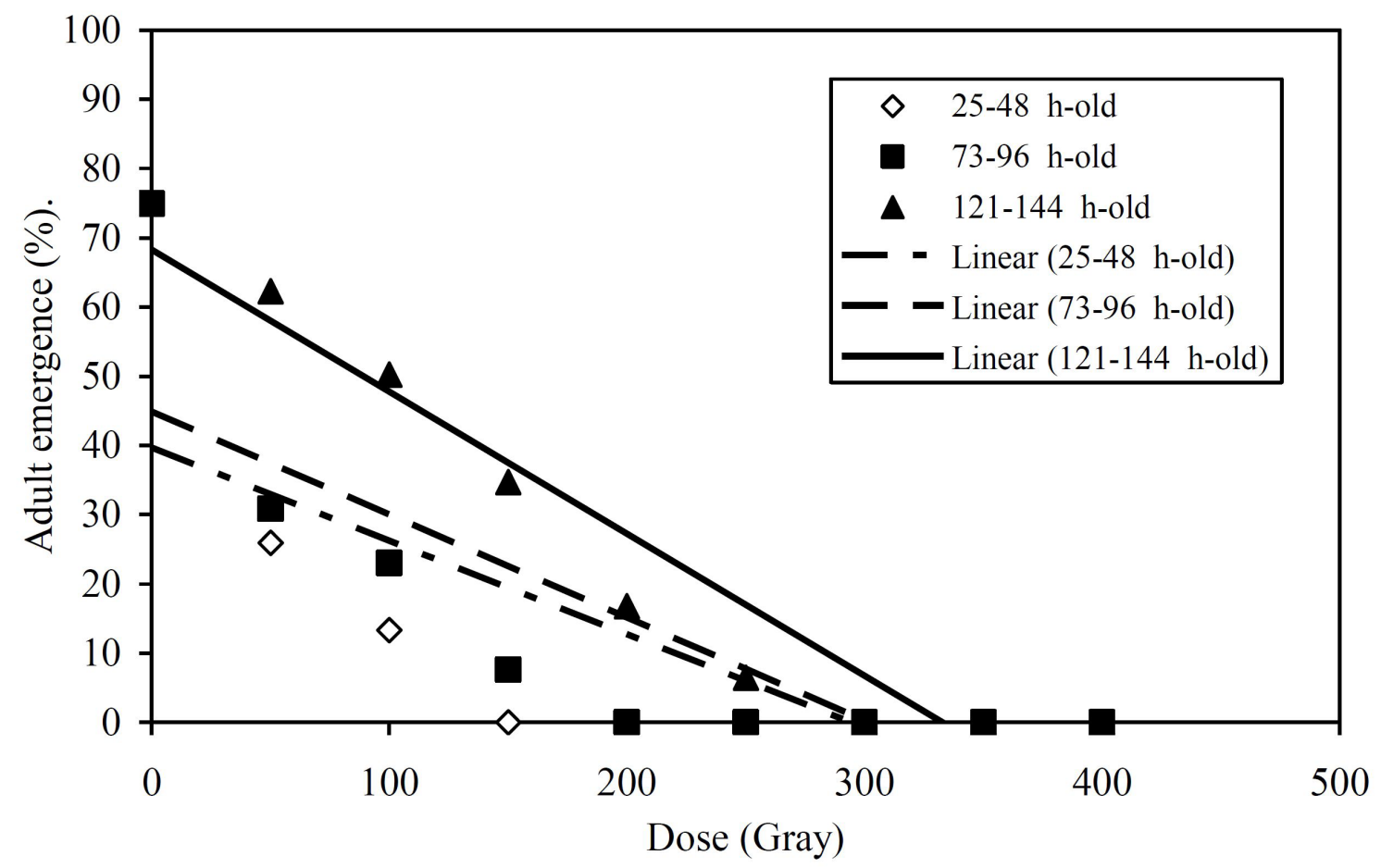

Fig. 3. Effects of gamma radiation on survival of $G$. mellonella larvae resulting from irradiated eggs to the adult stage.

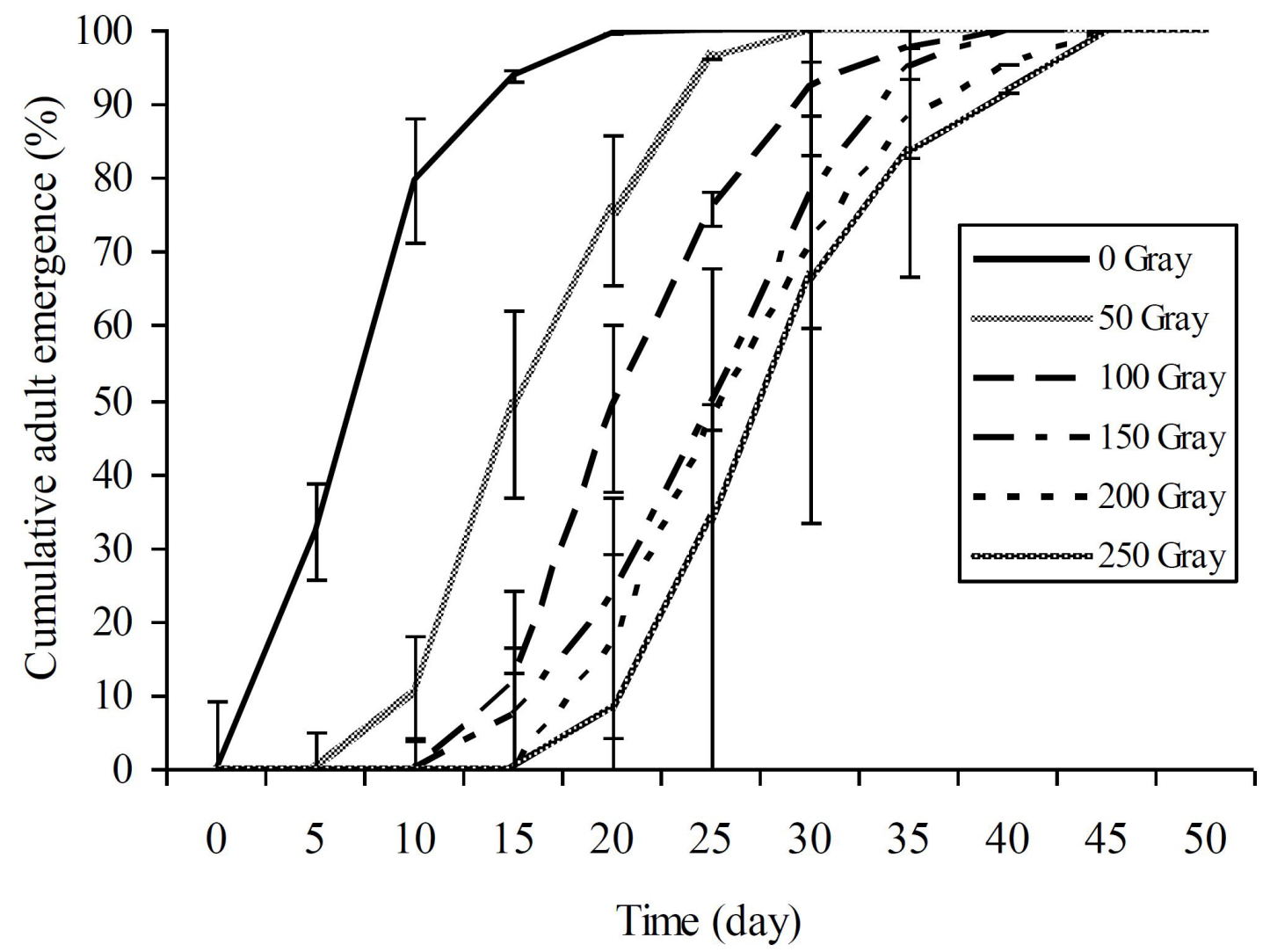

Fig. 4. Effects of gamma irradiation on the rate of development of immature stages resulting from 121-144 h-old irradiated eggs. 
effectiveness in some cases and danger from the standpoint of occupational safety. Furthermore, treatment with these chemicals takes a long time and, unfortunately, the most reliable fumigant (MB) is being phased out (Besri, 2010). To investigate the possible use of the irradiation disinfestation technique for a particular insect species, this species' radiosensitivity has to be established. In this report, the effects of gamma radiation on greater wax moth eggs is examined, in particular on egg hatch, pupation, adult emergence and rate of development of immature stages resulting from irradiated eggs. In addition, the required irradiation disinfestation dose for treating honeybee combs potentially infested with $G$. mellonella eggs is discussed.

The results of this study show that the sensitivity of G. mellonella eggs to gamma irradiation increased with increasing radiation dose and decreased with increasing age. While 200 Gy completely prevented egg hatching in 25-48 h-oldeggs, a dose of 400 Gy was needed to obtain the same result when 121-144 h-old eggs (hours before egg hatching) were irradiated. The effect was even stronger when considering survival to pupae or adults as a criterion for measuring effectiveness, and no pupae were recorded when 121-144 h-old eggs were exposed to 300 Gy dose. In fact, larvae resulting from eggs exposed to 300 Gy appear to have died within a short period of time following egg hatching, as no indication of any feeding or webbing activities was noticed in the larval diet. These results agree with those reported by Hallman et al., (2010) for a wide range of insect species. They also agree with data reported for many Lepidopterous pests (Ayvaz \& Tuncbileck, 2006; Ayvaz, Albayrak, \& Karaborklu, 2008; Ayvaz \& Yilmaz, 2015; Mansour, 2003, 2010, 2015, 2016; Mansour \& Mohamad, 2004; Mansour \& Al-Attar, 2012; Ozyardimci et al., 2006). The results, however, are different from those obtained by Milcheva (2004), who reported that a dose of 65 Gy was sufficient to prevent egg hatch in $G$. mellonella eggs treated hours before egg hatch (about the same stage of development). Differences in egg radiosensitivity with the current study may be related to differences in dose rates, experimental techniques and genetic variability among different strains (Hallman, 2000). Differences between laboratory colonies were also found to cause some differences in radiosensitivity (White, Koslinska, \& Suski, 1977). In addition, the actual delivered dose by Milcheva (2004) was not measured and, consequently, dosimetry cannot be excluded as one of the possible factors in explaining the differences between the two studies. However, it is difficult to relate all of these differences (65 vs. $400 \mathrm{~Gy}$ ) to the above mentioned factors. In addition, Lepidopteron, due to their holokinetik chromosomes, are the most tolerant insects to ionizing radiation, and other species belonging to the family Pyralidae are the most tolerant ones in this order (Bakri, Hether, \& Hendrichs, 2005). For instance, 350 Gy was needed to prevent the eggsof E. kuehniella (Mansour, 2010) and the Indian-meal moth Plodia interpunctella from hatching (Ayvaz et al., 2008). A slightly lower dose (300 Gy) was also required to cause a similar response in almond moth, E.cautella, eggs (Ozyardimci et al., 2006).

Irradiation also extended the developmental period of larvae resulting from irradiated G. mellonella eggs to the adult stage. While about $94 \%$ of control insects emerged within fifteen days of the start of moths emergence, none of the insects resulting from eggs exposed to 200 Gy and above emerged within this period. Delayed development of insects resulting from irradiated eggs has been reported before for several such insect species as Mediterranean flour moth, E. kuehniella, the Indian-meal moth, $P$. interpunctella, the mealy-bug, Dysmicoccus neobrevipes, and the grape vine moth, Lobesia botrana (Ayvaz et al., 2008; Ayvaz \& Tuncbilek, 2006; Mansour, 2010; Mansour \& Al-Attar, 2012; Thi et al., 2012)

These results could also be of value in rearing natural enemies, particularly egg parasitoids. G. mellonella eggs are a good host for rearing Trichogramma species (Boldt \& Marston, 1974). However, the rearing procedure requires host eggs to be killed before exposure to the parasitoid and irradiation offers a quick and affective way .

In summary, the results of this study show that 
gamma irradiation can possibly be used as a disinfestations treatment for honeybee combs potentially infested with G. mellonella eggs. The radiation disinfestations technique is safer than treatment with chemicals, and the required dose should not cause any undesirable changes in the treated product. The reliable technique provides quick and homogenous treatment and there is no fear of the pest developing resistance. However, this dose is intended to treat honeybee combs potentially infested with G. mellonella eggs only. Since newly stored combs may also carry G. mellonella larvae, or even pupae, the radiosensitivity of these two stages should be examined.

\section{ACKNOWLEDGEMENTS}

The author would like to thank Dr I. Othman, Director General of the Syrian Atomic Energy Commission and Dr F. Kurd-Ali, Head of the Department of Agriculture for supporting this project. This research was supported, in part, by the International Atomic Energy Agency, Vienna, Austria (Res. Contract No. SYR/19015).

\section{REFERENCES}

Ayvaz, A., \& Tuncbilek, A.S. (2006). Effects of gamma radiation on life stages of the Mediterranean flour moth Ephestia kuehniella Zeller (Lepidoptera: Pyralidae). Journal of Pest Science, 79(4), 215-222. DOl: https://doi.org/10.1007/s10340-006-0137-6

Ayvaz, A., Albayrak, S., \& Karaborklu, S. (2008). Gamma radiation sensitivity of the eggs, larvae and pupae of Indian meal moth Plodia interpunctella (Hübner) (Lepidoptera: Pyralidae). Pest Management Science, 64(5), 505-512. DOl: https://doi. org/10.1002/ps.1526

Ayvaz A., \& Yilmaz, S. (2015). "lonizing Radiation Disinfestation Treatments against Pest Insects", in: Evolution of Ionizing Radiation Research, Mitsuru Nenoi , Eds., InTech, Rijeka, pp. 235-258.

Babarinde, S.A., Odewole, A.F., Akinyemi, A.O., Adebayo, T.A., Olayioye, A., Omodehin, O.A., Alabi, O.F.
(2013). Control of wax moth, Galleria mellonella L. (Lepidoptera: Pyralidae) in post harvest honey comb. Advances in Life Science and Technology, 14, 41-44.

Bakri, A., Hether, N., \& Hendrichs J. (2005). Fifty years of radiation biology in Entomology: Lessons Learned from IDIDAS. Annals of the Entomological Society of America, 98(1), 1-12. DOl: https://doi. org/10.1603/0013-8746(2005)098[0001:FYORBI] 2.0.CO;2

Besri, M. (2010). The Montreal protocol and methyl bromide phase out in the dates sector. $4^{\text {th }}$ International date palm conference, Abu Dhabi, UAE, March 15-17, 2010. DOl: 10.17660/ActaHortic.2010.882.60

Boldt, P.E., \& Marston, N. (1974). Eggs of the greater wax moth as a host for Trichogramma. Environmental Entomology, 3(3), 545-548. DOl: https://doi. org/10.1093/ee/3.3.545

Charriere, J.D., \& Imdorf, A. (1999). Protection of honey combs from wax moth damage. American Bee Journal, 139(8), 627-630.

Follett, P. (2014). Phytosanitary irradiation for fresh horticultural commodities: generic treatment, current issues, and next steps. Stewart Postharvest Review. 3, 1 .

Goodman, R.D., Williams, P., Oldroyd, B. P. \& Hoffman, J. (1990). Studies on the use of phosphine gas for the control of greater wax moth (Galleria mellonella) in stored honeybee comb. American Bee Journal, 1307), 473-477.

Hallman, G.J. (2000). Expanding radiation quarantine treatments beyond fruit flies. Agricultural and Forest Entomology, 2(2), 85-95. DOl: https://doi. org/10.1046/j.1461-9563.2000.00057.x

Hallman, G.). (2001). Irradiation as a quarantine treatment. In: Food Irradiation: Principles and Applications. R. A. Molins (ed.). John Wiley \& Sons, Inc.

Hallman, G.J. (2014). Phytosanitary applications of irradiation. Comprehensive Reviews in Food Science and Food Safety, 102), 143-151. https://doi. 


\section{J. APRC. SCLI. VOL. 64 ND. 1 2020}

org/10.1111/j.1541-4337.2010.00144.x.

Hallman, G.J., Levang-Brilz, N. M., Zettler, J. L., \& Winborne, I. C. (2010). Factors affecting ionizing radiation phytosanitary treatments, and implications for research and generic treatments. Journal Economic Entomology, 103(6), 1950-1963. DOl: 10.1603/ ec10228

Haewoon, Man Young Duck O.L., \& Chang, C.P. (1995). Developing periods and damage patterns of combs by greater wax moth, Galleria mellonella. Korean Journal of Apiculture, 10, 5-10.

Kwadha, C.A., Ong'amo, G.O., Ndegwa, P.N., Raina, S.K., Fombong, A.T. (2017). The Biology and Control of the Greater Wax Moth, Galleria mellonella. Insects, 8(2), 1-17. DOl: 10.3390/insects8020061

Mansour, M.Y. (2003). Gamma irradiation as a quarantine treatment for apples infested by codling moth (Lepidoptera: Tortricidae). Journal of Applied Entomology, 1273), 137-141. https://doi.org/10.1046/ j.1439-0418.2003.00723.x

Mansour, M.Y. (2010). Effects of gamma radiation on the Mediterranean flour moth, Ephestia kuehniella, eggs and acceptability of irradiated eggs by Trichogramma cacoeciae females. Journal of Pest Science, 83(3), 243-249. https://doi.org/10.1007/s10340010-0291-8

Mansour, M.Y. (2015). Effects of gamma radiation on the Mediterranean flour moth, Ephestia kuehniella, mature larvae and acceptability of irradiated larvae by Bracon hebetor females. Journal of Stored Product Research, 60, 43-47. https://doi.org/10.1016/j. jspr.2014.10.003

Mansour, M.Y. (2016). Irradiation as a quarantine treatment for the Khapra beetle, Trogoderma granarium Everts (Coleoptera: Dermestidae). Florida Entomologist, 99, 138-142.

Mansour, M.Y., \& Mohamad, F., (2004). Effects of gamma irradiation on codling moth, Cydia pomonella (L.) eggs. Radiation Physics and Chemistry, 77(6), 1125-1128. https://doi.org/10.1016/j.radphy- schem.2003.12.051

Mansour, M.Y., \& Al-Attar, J. (2012). Effects of gamma irradiation on the grapevine moth, Lobesia botrana, eggs. Radiation Physics and Chemistry, 87(11), 1776-1780. https://doi.org/10.1016/j.radphyschem.2012.06.007

Milcheva, R.Y. (2004). Radiobiological studies on the Greater wax moth, Galleria mellonella L. (Lepidoptera: Pyralidae). I. lethal effects of gamma radiation on eggs and larvae. Bulgarian Journal of Agricultural Research, 10,663-668.

Morgan, A.C., \& Runner, G.A. (1913). Some experiments with Roentgen rays upon the cigarette beetle, Lasioderma sericorne Fabr. Journal of Economic Entomology 6, 226.

Nagaraja, N., \& Rajagopal, D. (2009). Honey Bees: Disease, parasites, pests, predators and their management. MJP publishers, Chennai, India. p210

Ozyardimci, B., Cetinkaya, N., Denli E, Ic E., \& Alabay M. (2006). Inhibition of egg and larval development of the Indian meal moth Plodia interpunctella (Hubner) and almond moth Ephestia cautella (Walker) by gamma radiation in decorticated hazelnuts. Journal of Stored Product Research, 42(2), 183-196. https:// doi.org/10.1016/j.jspr.2005.01.004

Rajendran, S., \& Hajira Parveen, K.M. (2005). Insect infestation in stored animal products, Journal of Stored Product Research, 47(1), 1-30, https://doi. org/10.1016/j.jspr.2003.12.002

Ritter, W., \& Akratanakul, P. (2006). Honey Bee Diseases and Pests: A Practical Guide; FAO: Rome, Italy, Volume 4.

Runner, G.A. (1916). Effects of Roentgen rays on the tobacco or cigarette beetle and results of experiment with a new form of Roentgen tube. Journal of Economic Entomology, 6, 383.

Simone-Finstroma, M., Aronsteina, K., Goblirschb, M., Rinkevicha, F., Guzmana, L. (2018). Gamma irradiation inactivates honey bee fungal, microsporidian, and vi- 


\section{- MAHSOUR Eefl.}

\section{Radiation effects on wax moth eggs}

ral pathogens and parasites. Journal of Invertebrate Pathology, 153, 57-64. https://doi.org/10.1016/j. jip.2018.02.011

Tananaki, C., Thrasyvoulou, A., Karazafiris, E., \& Zotou, A. (2006). Contamination of honey by chemicals applied to protect honeybee combs from wax moth (Galleria mellonella L.). Food Additives and Contaminants, 23(2), 159-163.

Thi, T.T., Nguyen, T.K., Vo, L.K.T., Cao, C.V., Tran, A.T.T., Nguyen, T.H.H. (2012). Effects of gamma irradiation on different stages of mealybug Dysmicoccus neobrevipes (Hemiptera: Pseudococcidae). Radiation Physics and Chemistry, 87(1), 97-100. https://doi. org/10.1016/..radphyschem.2011.09.014
White, L.D., Koslinska, M. \& Suski, Z.W. (1977). Codling moth: field-cage mating competitiveness of radio sterilized males. Journal of Economic Entomology. 70(1), 64-69. https://doi.org/10.1093/jee/70.1.64

Zhu, X.J., Zhou, S.J., Xu, X.J., Lan, H.H., Zhou, B.F. (2016). Freezing combs as a method for the greater wax moth (Galleria mellonella) control. Journal of Apiculture Research, 55(4), 351-352. https://doi.org/10.10 80/00218839.2016.1231457 